\title{
THE EFFECT OF OWNERSHIP STRUCTURE ON INCOME SMOOTHING
}

\author{
Dudi Pratomo ${ }^{1}$, Kurnia ${ }^{1}$, Adli Dzil Ikram ${ }^{1}$ \\ ${ }^{1}$ Universitas Telkom, Bandung, Indonesia \\ Email : dudipratomo@telkomuniversity.ac.id \\ Email : akukurnia@telkomuniversity.ac.id \\ Email : adlydzilfcb@student.telkomuniversity.ac.id
}

\begin{tabular}{|c|c|}
\hline INFO ARTIKEL & ABSTRAK/ABSTRACK \\
\hline $\begin{array}{l}\text { Histori Artikel : } \\
\text { Tgl. Masuk : } 12 \text { Maret } 2019 \\
\text { Tgl. Diterima : } 25 \text { Maret } 2019 \\
\text { Tersedia Online : } 29 \text { Maret } \\
2019 \\
\text { Keywords: } \\
\text { income smoothing, institutional } \\
\text { ownership, government } \\
\text { ownership, managerial } \\
\text { ownership. }\end{array}$ & $\begin{array}{l}\text { Income smoothing is an earnings management } \\
\text { action by raising or lowering earnings to make it look } \\
\text { more stable. This was done by company management } \\
\text { for reasons not achieving the company's targets. In } \\
\text { financial statements, a stable company profit illustrates } \\
\text { that the company had good business continuity. } \\
\text { Explained in the concept of corporate governance, } \\
\text { institutional ownership, government ownership, and } \\
\text { managerial ownership were believed to be able to } \\
\text { minimize the occurrence of income smoothing. } \\
\text { Therefore, this research was conducted to determine } \\
\text { the effect of institutional ownership, government } \\
\text { ownership, and managerial ownership with profitability } \\
\text { and leverage control variables on income smoothing } \\
\text { both simultaneously and partially in BUMN companies } \\
\text { listed on the Indonesia Stock Exchange in } 2012-2017 \text {. } \\
\text { The technique used to select samples was } \\
\text { purposive sampling technique. In the process, } 10 \\
\text { research samples were obtained with a period of } 6 \\
\text { years, so that } 60 \text { sample units were obtained. Then, to } \\
\text { carry out the analysis, the analytical method used } \\
\text { logistic regression analysis with the software used } \\
\text { SPSS 23.0. } \\
\text { After the analysis of this study, the results stated } \\
\text { that simultaneous institutional ownership, government } \\
\text { ownership, and managerial ownership with profitability } \\
\text { control variables and leverage had a significant } \\
\text { influence on income smoothing. Furthermore, partially } \\
\text { the results of this study stated that government } \\
\text { ownership had a significant effect on the negative } \\
\text { direction of income smoothing. While the other two } \\
\text { independent variables, namely institutional ownership } \\
\text { and managerial ownership variables did not have a } \\
\text { significant effect on income smoothing. }\end{array}$ \\
\hline
\end{tabular}

\section{PENDAHULUAN}

Teori keagenan mengatakan bahwa terjadinya hubungan keagenan apabila satu orang atau lebih bersepakat memberikan sebuah wewenang kepada orang lain untuk pengambilan keputusan (Jensen, M.C., and W.H. Meckling, 1976). Dalam hal ini pemberi wewenang adalah principal dan yang menerima wewenang adalah agent. Principal merupakan para pemilik saham dalam suatu perusahaan 
ataupun investor dan yang dimaksud dengan agent adalah manajemen dari perusahaan yang diberikan wewenang untuk mengelola perusahaan.

Manajemen sebagai pihak yang mengelola perusahaan dituntut untuk selalu meningkatkan kinerja dari perusahaan agar pemegang saham bisa mendapatkan kepuasan dari kinerja manajemen dan juga mendapatkan perhatian dari para investor. Laporan keuangan biasanya digunakan untuk mengukur kinerja manajemen dan juga perusahaan. Kasmir (2014:7), menyatakan bahwa kondisi keuangan dari sebuah perusahaan pada saat ini ataupun pada periode-periode tertentu dapat dilihat pada laporan keuangannya. Laporan keuangan dibuat dan disajikan oleh pihak manajemen. Dengan adanya laporan keuangan, informasi mengenai kinerja perusahaan dapat diketahui sehingga dapat membantu para pemakainya untuk mengambil sebuah keputusan. Tentunya, manajemen sebagai pihak yang membuat laporan keuangan akan lebih tahu secara rinci mengenai kondisi perusahaan dibanding para pemegang saham.

Manajemen bertanggungjawab kepada pemegang saham untuk memberitahu keadaan dari perusahaan. Namun, seringkali pihak manajemen memberikan informasi yang tidak sesuai atau berbeda dengan kondisi yang sebenarnya terjadi. Kejadian seperti ini dinamakan asimetri informasi (information asymetric). Salah satu penyebab terbukanya peluang manajemen untuk melakukan manajemen laba karena adanya asimetri informasi (Susanti, 2016).

Terdapat tiga jenis praktik manajemen laba yaitu manejemen melakukan increasing income (meninggikan laba) periode kini. Kemudian, manajer melakukan big bath dengan mengurangi laba pada suatu periode. Selanjutnya, manajer membuat laba lebih stabil dengan melakukan income smoothing (perataan laba). Perataan laba seringkali digunakan oleh manajer untuk menstabilkan laba untuk tahun yang akan datang dengan tahun terkini. Perataan laba dapat ditempuh dengan cara tahun yang memiliki pendapatan yang cukup tinggi, pendapatannya dialihkan untuk tahun dengan pendapatan rendah (Subramanyam dan Wild, 2014:108). Penelitian ini membahas tentang perataan laba yang merupakan bentuk dari manajemen laba. Perataaan laba adalah suatu tindakan yang disengaja yang bertujuan untuk mengurangi fluktuasi dari laba agar laba terlihat normal (Hery, 2016:51).

Tindakan perataan laba seringkali terjadi di Indonesia, salah sata contohnya adalah PT. Garuda Indonesia Tbk. (GIAA). GIAA terindikasi melakukan perataan laba setelah diketahui bahwa jajaran Direksi dari GIAA memberi arahan kepada Kepala Unit dan Kepala Bagian Akunting untuk melakukan perubahan dalam laporan keuangan GIAA dengan cara menangguhkan biaya-biaya non rutin pada Juni 2015 ke Juli atau Agustus 2015. Tidak hanya itu, GIAA juga melakukan penundaan pembayaran utang dan akan diakui pada bulan Juli atau Agustus 2015. Tindakan ini dilakukan agar laporan keuangan dapat terlihat lebih baik (www.energyworld.co.id).

Dalam penelitian ini, terdapat tiga jenis struktur kepemilikan yang diduga dapat meminimalisir praktik perataan laba antara lain kepemilikan institusional, kepemilikan pemerintah, dan kepemilikan manajerial. Variabelvariabel tersebut sebelumnya sudah digunakan oleh beberapa penelitian terdahulu. Namun, dalam penelitianpenelitian terdahulu para peneliti menggabungkan antara kepemilikan oleh swasta dan juga oleh pemerintah dalam kepemilikan institusional.

Berbeda dengan penelitian sebelumnya, kepemelikan institusional dalam penelitian ini meliputi lembaga atau institusi yang dimiliki oleh pihak swasta baik domestik ataupun asing, kemudian kepemilikan pemerintah yang dimaksud adalah lembaga atau institusi 
yang dimiliki oleh negara atau pemerintah, dan kepemilikan manajerial adalah saham institusi ataupun lembaga yang dimiliki oleh manajer perusahaan itu sendiri.

Kepemilikan institusional merupakan saham institusi ataupun lembaga seperti bank, perusahaan asuransi ataupun investasi, perusahaan luar negeri ataupun dalam negeri, pemerintah dan institusi lainnya yang ditanamkan pada sebuah perusahaan. Namun, dalam penelitian ini kepemilikan institusional yang berasal dari saham pemerintah tidak dianggap sebagai kepemilikan institusional tapi dianggap sebagai kepemilikan pemerintah. Kepemilikan pemerintah meliputi saham-saham yang ditanamkan pemerintah pada suatu perusahaan. Kepemilikan pemerintah ini sangat mudah ditemukan pada perusahaan-perusahaan plat merah yaitu perusahaan BUMN. Kemudian, kepemilikan saham perusahaan yang dimiliki oleh manajer pada perusahaan itu sendiri biasa disebut dengan saham manjerial. Meilitia dan Rokhmawati (2017), menyatakan bahwa kepemilikan manajerial merupakan suatu kondisi dimana manajer bertugas untuk mengelola perusahaan dan juga bertugas mengawasi kinerja manajemen sebagai pemegang saham.

Adapun dilakukannya penelitian ini yaitu agar dapat mengetahui pengaruh dari kepemilikan institusional, kepemilikan pemerintah, dan kepemilikan manajerial dengan variabel kontrol profitabilitas dan leverage terhadap perataan laba secara parsial ataupun simultan pada perusahaan BUMN yang terdaftar di Bursa Efek Indonesia (BEI) tahun 2012-2017.

\section{KERANGKA TEORITIS DAN PENGEMBANGAN HIPOTESIS}

\section{Teori Keagenan}

Teori keagenan mengatakan bahwa terjadinya hubungan keagenan apabila satu orang atau lebih bersepakat memberikan sebuah wewenang kepada orang lain untuk pengambilan keputusan (Jensen, M.C., and W.H. Meckling, 1976). Dengan kata lain, manajemen memiliki tanggung jawab kepada pemegang saham atau investor untuk melaporkan kondisi perusahaan melalui penerbitan laporan keuangan. Akan tetapi, seringkali informasi yang disampaikan manajemen kepada pemegang saham atau investor berbeda dengan keadaan sebenarnya. Hal seperti ini disebut dengan asimetri informasi (information asymetric).

\section{Tata Kelola Perusahaan}

Tata kelola perusahaan (corporate governance) merupakan konsep yang bertujuan untuk mengarahkan dan mengambil kendali pengelolaan perusahaan agar kepentingan para pemegang saham dapat terlindungi dan tercapai (Yadiati dan Mubarok, 2017:89). Efektivitas perusahaan tidak berjalan dengan baik ketika terdapat perbedaan kepentingan antara pemegang saham dan manajemen. Salah satu caranya dijelaskan oleh konsep corporate governance yaitu dengan struktur kepemilikan. Sturktur kepemilikan diyakini dapat meminimalisir munculnya masalahmasalah di dalam perusahaan karena memiliki kemampuan untuk mempengaruhi jalannya sebuah perusahaan.

\section{Struktur Kepemilikan}

Struktur kepemilikan dapat didefinisikan sebagai sejumlah saham yang dimiliki oleh orang-orang yang berada pada lingkup internal perusahaan ataupun investor (Ulfiyati et al, 2017). Dalam struktur kepemilikan, jenis dari suatu kepemilikan terdiri atas dua yaitu kepemilikan institusonal dan kepemilikan manajerial. Kepemilikan ini memiliki mekanisme masing-masing dalam melakukan monitoring terhadap manajemen agar kinerja perusahaan menjadi lebih baik.

\section{Kepemilikan Instituional}


Menurut Pasaribu et al (2016) dan Mahariana dan Ramantha (2016) mengemukakan bahwa kepemilikan institusional ialah persentase kepemilikan saham dari suatu institusi pada sebuah perusahaan. Fahdiansyah et al (2018) juga mengemukakan bahwa kepemilikan institusional dapat mengawasi manajemen dengan sangat optimal sehingga manajemen sulit untuk melakukan tindakan-tindakan yang menyimpang.

\section{Kepemilikan Pemerintah}

Kepemilikan pemerintah merupakan kepemilikan saham dalam perusahaan yang dimiliki oleh pemerintah dan kepemilikan jenis ini biasa ditemukan pada perusahaan-perusahaan negara atau perusahaan BUMN (Setiawan et al, 2016). Dalam teori keagenan menyatakan bahwa sebuah perusahaan yang terdapat kepemilikan pemerintah akan menyulitkan manajemen untuk bertindak sewenang-wenang. Akan tetapi, banyak pendapat yang mengemukakan bahwa adanya kepemilikan pemerintah membuat kinerja perusahaan menjadi tidak lebih baik. Capalbo et al (2018) mengemukakan bahwa intervensi yang dilakukan pemerintah terhadap manajemen didasarkan pada kepentingan politis dan bukan untuk meningkatkan kinerja perusahaan.

\section{Kepemilikan Manajerial}

Struktur kepemilikan saham yang kepemilikannya dimiliki oleh manajer pada perusahaan tersebut biasa dikatakan sebagai kepemilikan manajerial. Meilitia dan Rokhmawati (2017) mengemukakan bahwa kepemilikan manajerial merupakan suatu kondisi dimana manajer bertugas untuk mengelola perusahaan dan juga bertugas mengawasi kinerja manajemen sebagai pemegang saham. Dalam konsep corporate governance meyakini bahwa kepemilikan manajerial dapat membantu meminimalisir tindakan penyimpangan yang dilakukan oleh manajemen.
Perataaan laba merupakan sebuah tindakan untuk mengurangi dengan sengaja fluktuasi atas laba agar laba terlihat normal (Hery, 2016:51). Subramanyam dan Wild (2014:108) menyatakan bahwa tindakan perataan laba adalah tindakan mengolah laba dengan menaikkan atau menurunkan laba agar laba dari tahun ke tahun tidak terlalu berfluktuasi. Pengukuran perataan laba dapat dihitung menggunakan Indeks Eckel (1981).

\section{Pengaruh Kepemilikan Institusional Terhadap Perataan Laba}

Menurut Fahdiansyah et al (2018), adanya kepemilikan institusional diyakini bahwa ada pihak yang dapat mengawasi manajemen dengan tujuan untuk meminimalisir tindakan perataan laba dalam suatu perusahaan.

Penelitian dari Husaini dan Sayunita (2016) dan Pratiwi dan Damayanthi (2017), menunjukkan hasil yaitu kepemilikan institusional berpengaruh signifikan dengan arah negatif terhadap perataan laba. Kepemilikan institusional diyakini dapat meminimalisir adanya praktik perataan laba.

\section{Pengaruh Kepemilikan Pemerintah Terhadap Perataan Laba}

Teori keagenan menjelaskan bahwa pemerintah sebagai pemegang saham pengendali harus mengontrol dan mengawasi kinerja dari manajemen, tetapi fakta yang ada bahwa pemerintah lebih mementingkan kepentingan politik daripada memikirkan untuk meningkatkan kinerja perusahaan. Sehingga tidak tercapainya fungsi controlling kepada manajemen yang memicu terjadinya tindakan perataan laba.

Adapun hasil dari penelitian oleh Yang et al (2012), menemukan hasil bahwa kepemilikan pemerintah memiliki pengaruh signifikan dengan arah positif terhadap perataan laba yang berarti dengan adanya kepemilikan pemerintah dalam perusahaan akan memberikan peluang untuk melakukan tindakan perataan laba. 


\section{Pengaruh Kepemilikan Manajerial Terhadap Perataan Laba}

Dalam konsep coporate governance, kepemilikan manajerial dalam suatu perusahaan diyakini mampu mengurangi konflik antar manajemen dan pemegang saham yang dikarenakan oleh perbedaan kepentingan. Ketika seorang manajer memiliki kepemilikan yang cukup besar maka segala keputusan akan dipilih dengan teliti agar tidak merugikan perusahaan dan berarti bahwa manajer akan menghindari tindakan perataan laba.

Penelitian oleh Mahariana dan Ramantha (2014) dan Aryanti dan Hendratno (2017), menyatakan bahwa kepemilikan manajerial berpengaruh dengan arah negatif terhadap perataan laba yang berarti bahwa kepemilikan manajerial dalam suatu perusahaan dapat meminimalisir terjadinya praktik perataan laba.

\section{METODOLOGI PENELITIAN}

\section{Metodologi}

Untuk melakukan analisis, penelitian ini menggukan metode kuantitatif. Kemudian, perusahaan BUMN yang terdaftar di Bursa Efek Indonesia (BEI) pada tahun 2012-2017 dijadikan populasi dalam penelitian ini. Penelitian ini juga menerapkan metode purposive sampling untuk melakukan seleksi terhadap sampel, setelah melewati proses seleksi dihasilkan 60 unit sampel, sampel tersebut terdiri dari 10 perusahaan selama 6 tahun. Selanjutnya, untuk melakukan analisis digunakan metode analisis regresi logistik dengan persamaan sebagai berikut:

$$
P L=\propto+\beta_{1} K I+\beta_{2} K P+\beta_{3} K M+\beta_{4} P+\beta_{5} L+\varepsilon
$$

Keterangan:

PL : Perataan Laba, ( kategori 1 = Perusahaan perata laba dan kategori 0 = Perusahaan bukan perata laba ).

$\propto \quad$ : Konstanta.

$$
\begin{array}{ll}
\text { KI } & \text { : Kepemilikan Institusional. } \\
\text { KP } & \text { : Kepemilikan Pemerintah. } \\
\text { KM } & : \text { Kepemilikan Manajerial. } \\
\mathrm{P} & : \text { Profitabilitas } \\
\mathrm{L} & : \text { Leverage } \\
\beta & : \text { Koefisien regresi variabel } \\
\varepsilon & : \text { Error term. }
\end{array}
$$

\section{Pengukuran Variabel}

a. Perataan laba

Perataan laba diukur dengan menggunakan rumus Indeks Eckel (1981) dalam Brilliano dan Khairunnisa (2016) adalah sebagai berikut:

Indeks Perataan Laba $=\frac{\mathrm{CV} \Delta \mathrm{I}}{\mathrm{CV} \Delta \mathrm{S}}$

Keterangan:

$$
\begin{aligned}
\Delta \mathrm{I}= & \begin{array}{l}
\text { Perubahan nilai pada laba } \\
\text { bersih }
\end{array} \\
\Delta \mathrm{S}= & \begin{array}{l}
\text { Perubahan nilai pada } \\
\text { penjualan }
\end{array} \\
\mathrm{CV}= & \begin{array}{l}
\text { Coefficient Variation laba } \\
\text { bersih/penjualan, }
\end{array} \\
& \text { merupakan hasil pembagian } \\
& \text { dari standar deviasi laba } \\
& \text { bersih/penjualan dan rata- } \\
& \text { rata laba bersih/penjualan. }
\end{aligned}
$$

Setelah CV dari laba bersih maupun penjualan dibagi, hasil dari pembagiannya kemudian dijadikan dummy variable. Angka 0 dikategorikan sebagai perusahaan yang tidak terindikasi sebagai perataa laba dan angka 1 dikategorikan sebagai perusahaan yang terindikasi sebagai perusahaan perata laba (Brilliano dan Khairunnisa, 2016).

b. Kepemilikan Institusional

Dalam penelitian ini variabel kepemilikan institusional diukur menggunakan rumus menurut Suryani dan Damayanti (2015) adalah sebagai berikut:

$$
K I=\frac{\text { Jumlah Saham Institusional }}{\text { Jumlah Saham yang Beredar }}
$$


c. Kepemilikan Pemerintah

Dalam penelitian ini variabel kepemilikan pemerintah diukur menggunakan rumus menurut Kurniawati dan Komalasari (2014) adalah sebagai berikut:

$K P=\frac{\text { Jumlah Saham Pemerintah }}{\text { Jumlah Saham yang Beredar }}$

d. Kepemilikan Manajerial

Dalam penelitian ini variabel kepemilikan pemerintah diukur menggunakan rumus menurut Kurniawati dan Komalasari (2014) adalah sebagai berikut:

$K M=\frac{\text { Jumlah Saham Manajerial }}{\text { Jumlah Saham yang Beredar }}$

\section{HASIL DAN PEMBAHASAN}

\section{Analisis Statistik Deskriptif}

Tabel 1. Uji Statistik Deskriptif

\begin{tabular}{|l|c|c|c|c|c|}
\hline & N & Min & Maks & Mean & $\begin{array}{c}\text { Std. } \\
\text { Deviation }\end{array}$ \\
\hline KI & 60 & 0,0000 & 0,7106 & 0,0445 & 0,12889 \\
KP & 60 & 0,0000 & 0,9489 & 0,6051 & 0,16918 \\
KM & 60 & 0,0000 & 0,0046 & 0,0002 & 0,00067 \\
P & 60 & 0,0109 & 0,2330 & 0,0812 & 0,05889 \\
L & 60 & 0,1103 & 0,8500 & 0,5287 & 0,18636 \\
PL & 60 & 0,0000 & 1,0000 & 0,4833 & 0,50394 \\
N & 60 & & & & \\
\hline
\end{tabular}

Sumber: Output SPSS 23.0

Dapat dilihat pada tabel 1 di atas, terdapat nilai minimum, nilai maksimum, rata-rata (mean), dan standar deviasi untuk $\mathrm{N}$ (jumlah keseluruhan) sejumlah 60 sampel. Hasilnya semua data adalah valid dari seluruh variabel penelitian, yaitu kepemilikan institusional (KI), kepemilikan pemerintah (KP), kepemilikan manajerial (KM), dan perataan laba $(\mathrm{PL})$.
Analisis Regresi Logistik

a. Hosmer and Lemeshow's Test

Tabel 2 Hosmer and Lemeshow's

Test

\begin{tabular}{|c|c|c|c|}
\hline Step & $\begin{array}{c}\text { Chi- } \\
\text { square }\end{array}$ & df & Sig. \\
\hline 1 & 4,318 & 8 &, 827 \\
\hline
\end{tabular}

Berdasarkan tabel 2 di atas, hasil dari pengujian Hosmer and Lemeshow's, menghasilkan nilai chisquare sebesar 4,318 dengan signifikasi 0,827 . Pada pengujian Hosmer and Lemeshow's, tingkat dari signifikansinya yaitu nilai $\operatorname{sig}>\alpha(0,05)$. Jika terpenuhi, maka hipotesis $0(\mathrm{H} 0)$ diterima dan model dapat diterima.

\section{b. Menilai Model Fit}

Tabel 3 Overall Model Fit Overall Model Fit (-2LogL)

\begin{tabular}{l|l|}
\hline -2LogL Block Number $=0$ & 83,111 \\
\hline -2LogL Block Number $=1$ & 68,620 \\
\hline \multicolumn{2}{|c|}{ Sumber: Output SPSS 23.0 }
\end{tabular}

Dari tabel 3 di atas, menunjukkan hasil bahwa nilai -2LogL Block Number $=0$ adalah sebesar 83,111. Sedangkan nilai -2LogL Block Number $=1$ menunjukkan nilai yang lebih kecil sebesar 68,620. Dari perbandingan di atas dapat dilihat bahwa terdapat penurunan nilai sebesar 14,491 sehingga dapat dibuktikan bahwa variabel kepemilikan institusional, kepemilikan pemerintah, dan kepemilikan manajerial dengan variabel kontrol profitabilitas dan leverage dengan signifkan dapat memperbaiki model fit.

c. Koefisien Determinasi (R2)

Tabel 4 Model Summary

\begin{tabular}{|c|c|c|c|}
\hline Step & $\begin{array}{c}\mathbf{- 2 L o g} \\
\text { Likelihood }\end{array}$ & $\begin{array}{c}\text { Cox \& } \\
\text { Snell } \boldsymbol{R} \\
\text { Square }\end{array}$ & $\begin{array}{c}\text { Nagelkerke } \boldsymbol{R} \\
\text { Square }\end{array}$ \\
\hline 1 & $68,260^{\mathrm{a}}$ &, 219 &, 292 \\
\hline
\end{tabular}

Sumber: Output SPSS 23.0 
Pada tabel 4 menghasilkan nilai Nagelkerke $R$ Square yaitu 0.292 lebih besar dari nilai Cox \& Snell $R$ Square yaitu 0,219. Dengan ini dapat disimpulkan bahwa kemampuan variabel independen yaitu kepemilikan institusional, kepemilikan pemerintah, dan kepemilikan manajerial dengan variabel kontrol profitabilitas dan leverage dapat berpengaruh terhadap variabel dependen sebesar $29,2 \%$, dan adapun sisanya sebesar $70,8 \%$ dapat dipengaruhi oleh variabel yang tidak digunakan di dalam penelitian ini

\section{d. Pengujian Simultan (Uji F)}

Tabel 5 Omnibus Test of Model Coefficients

\begin{tabular}{|cc|c|c|c|}
\hline & & $\begin{array}{c}\text { Chi- } \\
\text { square }\end{array}$ & df & Sig. \\
\hline Step & Step & 14,851 & 5 &, 011 \\
& & & & \\
& Block & 14,851 & 5 &, 011 \\
& Model & 14,851 & 5 &, 011 \\
\hline \multicolumn{2}{|c|}{ Mon }
\end{tabular}

Sumber: Output SPSS 23.0

Tabel 5 memperlihatkan hasil untuk menilai pengujian simultan. Nilai dari chi-square adalah sebesar 14,851, dengan nilai $d f$ adalah 5 serta nilai sig. adalah 0.011 (sig. < 0.05), maka $\mathrm{H}_{01}$ ditolak dan $\mathrm{H}_{\mathrm{a} 1}$ diterima. $\mathrm{H}_{\mathrm{a} 1}$ diterima berarti kepemilikan institusional, kepemilikan pemerintah, dan kepemilikan manajerial dengan variabel kontrol profitabilitas dan leverage secara simultan berpengaruh signifikan terhadap perataan laba.

\section{e. Pengujian Parsial (Uji T)} Tabel 6 Variables in the Equation

\begin{tabular}{|l|l|l|l|l|l|l|l|}
\hline \multicolumn{2}{|l|}{} & $B$ & S.E. & Wald & df & Sig. & $\operatorname{Exp(B)}$ \\
\hline $\begin{array}{l}\text { Step } \\
1^{\text {a }}\end{array}$ & KI & $-1,747$ & 3,520 &, 246 & 1 &, 620 &, 174 \\
& KP & $-5,381$ & 2,580 & 4,350 & 1 &, 037 &, 005 \\
& KM & 323,300 & 436,736 &, 548 & 1 & 0,459 & $2,556+140$ \\
& P & $-29,012$ & 10,293 & 7,945 & 1 & 0,005 &, 000 \\
& L & $-6,416$ & 2,769 & 5,368 & 1 & 0,021 &, 002 \\
& Constant & 8,956 & 3,192 & 7,873 & 1 & 0,005 & 7757,743 \\
\hline
\end{tabular}

Sumber: Output SPSS 23.0
Dari tabel 6 di atas, disimpulkan bahwa:

1) Nilai sig. kepemilikan institusional adalah sebesar $0,620>\alpha=0,05$. Dengan adanya hasil ini dapat dikatakan bahwa $\mathrm{H}_{\mathrm{a} 1}$ tidak diterima sedangkan $\mathrm{H}_{01}$ diterima. Hasil ini berarti bahwa secara parsial kepemilikan institusional tidak memiliki pengaruh terhadap perataan laba.

2) Nilai sig. kepemilikan pemerintah adalah sebesar $0,037<\alpha=0,05$. Dengan adanya hasil ini dapat dikatakan bahwa $\mathrm{H}_{\mathrm{a} 1}$ diterima dan $\mathrm{H}_{01}$ tidak diterima. Hasil ini berarti bahwa secara parsial kepemilikan pemerintah berpengaruh signifikan terhadap perataan laba.

3) Nilai sig. kepemilikan manajerial adalah sebesar 0,459> $\alpha=0,05$. Dengan adanya hasil ini dapat dikatakan bahwa $\mathrm{H}_{\mathrm{a} 1}$ tidak diterima dan $\mathrm{H}_{01}$ diterima. Hasil ini berarti bahwa secara parsial kepemilikan manajerial tidak berpengaruh terhadap perataan laba.

\section{Persamaan Model Regresi}

Dari hasil pengujian, dapat dihasilkan persamaan model regresi seperti berikut:

\section{$\mathrm{PL}=8,956-1,747 \mathrm{KI}-5,381 \mathrm{KP}$}

$+323,300 K M-29,012 P-6,416 L+\varepsilon$

Keterangan:

KI : Kepemilikan Institusional

KP : Kepemilikan Pemerintah

KM : Kepemilikan Manajerial

$\mathrm{P} \quad$ : Profitabilitas

L : Leverage

E : Error

Penjelasan persamaan regresi:

1) Nilai dari hasil konstanta adalah sebesar 8,956, hasil ini menjelaskan bahwa jika variabel independen dalam penelitian yaitu kepemilikan institusional, kepemilikan pemerintah, dan kepemilikan manajerial dengan variabel kontrol profitabilitas dan leverage bernilai sama dengan 0 , maka menurut eckel index berarti 
bahwa perusahaan tersebut melakukan tindakan perataaan laba.

2) Nilai $\beta_{1}-1,747$, dapat menjelaskan bahwa apabila kepemilikan institusional meningkat sebesar 1 satuan, maka penurunan atas indeks perataan laba akan terjadi yaitu sebesar 1,747.

3) Nilai $\beta_{2}-5,381$, dapat menjelaskan bahwa apabila kepemilikan pemerintah meningkat sebesar 1 satuan, maka penurunan atas indeks perataan laba akan terjadi yaitu sebesar 5,381.

4) Nilai $\beta_{3} 323,300$, dapat menjelaskan bahwa jika kepemilikan manajerial meningkat sebesar 1 satuan, maka kenaikan indeks praktik perataan laba akan terjadi yaitu sebesar 323,300 .

5) Nilai $\beta_{4}-29,012$, dapat menjelaskan bahwa jika profitabilitas meningkat sebesar 1 satuan, maka penurunan atas indeks perataan laba akan terjadi yaitu sebesar 29,012.

6) Nilai $\beta_{5}-6,416$, dapat menjelaskan bahwa jika leverage meningkat sebesar 1 satuan, maka penurunan atas indeks perataan laba akan terjadi yaitu sebesar 6,416.

\section{KESIMPULAN}

Penelitian ini ditujukan agar pembaca ataupun pengguna dapat mengetahui bagaimana variabel dependen (perataan laba) dapat dipengaruhi oleh variabel independen yaitu kepemilikan institusional, kepemilikan pemerintah, dan kepemilikan manajerial bersama dengan varibel kontrol profitabilitas dan leverage pada perusahaan BUMN yang terdaftar di Bursa Efek Indonesia pada tahun $2012-2017$.

Adapun hasil dari penelitian ini menyatakan bahwa kepemilikan institusional dan kepemilikan manajerial belum mampu dijadikan solusi untuk mengurangi praktik perataan laba pada perusahaan BUMN yang terdaftar di
BEI periode 2012-2017. Sedangkan kepemilikan pemerintah diyakini dapat mengurangi praktik perataan laba pada perusahaan BUMN yang terdaftar di BEI periode 2012-2017.

\section{IMPLIKASI DAN KETERBATASAN}

\section{Keterbatasan}

Dalam melakukan penelitian ini, ada beberapa keterbatasanketerbatasan yang dialami oleh peneliti antara lain, sampel dalam penelitian ini hanya berfokus pada perusahaan BUMN yang terdaftar di BEI. Kemudian, selama periode penelitian yaitu pada periode 2012-2017 banyak perusahaan yang tidak konsisten menerbitkan laporan keuangannya sehingga perusahaan tersebut harus dieliminasi berdasarkan kriteria dari purposive sampling.

\section{Saran}

Peneliti selanjutnya diharapkan dapat menggunakan variabel-variabel independen lainnya selain yang digunakan pada penelitian ini seperti, income tax, asimetri informasi, corporate governance, nilai saham, kepemilikan publik, kepemilikan karyawan, kualitas auditm komite audit, umur perusahaan, dan lain-lain.

Peneliti selanjutnya juga diharapkan dapat mencoba untuk menambahkan periode penelitian pada objek perusahaan BUMN yang terdaftar di BEI ataupun dapat mengganti objek penelitian dengan objek-objek lainnya.

\section{REFERENCES}

Aryanti, I., \& Hendratno, F. T. K. (2017). Kepemilikan Institusional, Kepemilikan Manajerial, dan Kualitas Audit Terhadap 
Manajemen Laba. Jurnal Riset Akuntansi Kontemporer (JRAK), 9(2), 66-70.

Brilliano, Arief., \& Khairunnisa. (2016). Pengaruh Komite Audit, Ukuran Perusahaan, Pajak, Kepemilikan Manajerial, dan Kualitas Audit Terhadap Perataan Laba ( Studi Empiris Pada Emiten Sektor Manufaktur yang terdaftar di Bursa Efek Indonesia Pada Tahun 2011-2015 ). eProceeding of Management, 3(3), 2355-9357

Capalbo, Francesco., M. S., \& M.S. (2018). Earnings Management and State Ownership: A Literature Review. International Journal of Business and Management; Vol. 13, No. 6; 2018 ISSN 1833-3850; E-ISSN 1833-8119.

Fahdiansyah, Restu., Qudsi, Jihadil., \& Bachtiar, Adam. (2017). Struktur Kepemilikan dan Nilai Perusahaan: (Studi Pada Perusahaan Manufaktur Yang Listing di Bursa Efek Indonesia). Jurnal Varian Vol. 1 No. 2 Maret 2018; E-ISSN 2581-2017.

Hery. (2016). Analisis Laporan Keuangan. Yogyakarta: CAPS.

Husaini., \& Sayunita. (2016). Determinant of Income Smoothing At Manufacturing Firms Listed On Indonesia Stock Exchange. International Journal of Bussiness and m/Anagement Invention, 5(9), 5-8.

Jensen, M.C., and W.H. Meckling. (1976). Theory of The Firm: Managerial Behaviour, Agency Cost, and Ownership Structure. Journal of Financial and Economics 3: 305-360

Kasmir. (2014). Analisis Laporan Keuangan. Jakarta: PT. Rajagrafindo Persada.

Kurniawati, Indah., \& Komalasari, Puput Tri. (2014). Pengaruh Kepemilikan Negara Terhadap
Corporate Risk Taking. Jurnal Manajemen Teori dan Terapan Tahun 7. No. 2, Agustus 2014.

Mahariana, I.D.G.P., \& Ramantha, I.W. (2014). Pengaruh Kepemilikan Manajerial dan Kepemilikan Institusional pada Nilai

Perusahaan. E-Jurnal Akuntansi Universitas Udayana, Faktor, F.(9.3), 575-590.

Meilita, Willi., \& Rokhmawati, Andewi. (2017). Pengaruh Kepemilikan Manajerial, Kepemilikan Institusional, Kepemilikan Asing, Kepemilikan Individu, Kebijakan Hutang dan Dividen Tahun Sebelumnya Beroengaruh Terhadap Kebijakan Dividen. Jurnal Tepak Manajemen Bisnis Vo. IX. No. 2 Mei 2017.

Pasaribu, Mirry Yuninyanti., Topowijono., \& S.S. (2016). Pengaruh Struktur Modal, Struktur Kepemilikan, dan Profitabilitas Terhdap Nilai Perusahaan Pada Perusahaan Sektor Industri Dasar dan Kimia Yang Terdaftar di BEI Tahun 2011-2014. Jurnal Administrasi Bisnis (JAB) Vol. 35 No.1 Juni 2016.

Pratiwi, N. W. P. I., \& Damayanthi, I. G. A. E. (2017). Analisis Perataan Laba dan Faktor-faktor yang Mempengaruhinya. E-Jurnal Akuntansi Universitas Udayana, 20(1), 496-525.

RHZ. (2016, 20 Maret). Kasus BUMN: Sejak Juni 2015 Keuangan PT. Garuda Indonesia Sudah Dimanipulasi. Energy World [online]. HYPERLINK "http://www.energyworld.co.id" www.energyworld.co.id September 2018]

Sahamok. (2016, 12 Agustus). Daftar Perusahaan BUMN Publik di BEI [online].

www.sahamok.com

September 2018].

Setiawan, Doddy., \& B. B. (2016). Ownership Structure and 
Dividen Policy in Indonesia. Journal of Asia Business Studies Vol. 10 No. 32016 ISSN 1558-7894.

Subramanyam, K.R., \& Wild, John. J. (2014). Analisis Laporan Keuangan. Jakarta: Salemba Empat.

Suryani, Ayu, D, \& Damayanti, E.A.G.I. (2015). Pengaruh Ukuran Perusahaan, Debt to Equity Ratio, Profitabilitas dan Kepemilikan Institusional Pada Perataan Laba. E-Jurnal Akuntansi Universitas Udayana 13.1 (2015): 208-223, ISSN: 2302-8556.

Susanti, Ayu (2016). Pengaruh Asimetri Informasi, Ukuran Perusahaan, Kepemilikan Manajerial, dan Capital Adequacy Ratio Terhadap Manajemen Laba. JOM Fekon, Vol.3 No.1 (Februari) 2016.

Ulfiyati, L. L. (2017). Analisis Perbedaan Struktur Kepemilikan Asing dan Struktur Kepemilikan Domestik Pada Perusahaan Pertambangan Di Bursa Efek Indonesia. Jurnal EMBA Vol. 5 No.2 Juni 2017; ISSN 2303-1174.

Yadiati, W. \& Mubarok (2017). Kualitas Laporan Keuangan. Jakarta: Kencana.

Yang, C.Y., Tan, L.B., \& Ding, Xiaoming. (2012). Corporate Governance and Income Smoothing in China. Journal of Financial Reporting and Accounting Vol. 10 No. 2, 2012. 120-139. 